\title{
Fitness and microsatellite diversity estimates were not correlated in two outbred anuran populations
}

\author{
GRAHAM ROWE \& TREVOR J. C. BEEBEE* \\ School of Biological Sciences, University of Sussex, Falmer, Brighton BN1 9QG, UK
}

\begin{abstract}
Larval fitness traits were investigated in two anuran species (Bufo calamita and Rana temporaria) under controlled laboratory conditions, and allelic diversity measured in the same individuals at five and seven microsatellite loci, respectively. For both species there were significant differences among sibships in larval growth and development rates, and in some cases also in microsatellite heterozygosity and mean $d^{2}$ (a measure of diversity based on differences in allele sizes). However, there were no significant correlations between any of the fitness and genetic measures either among all individuals, among sibships or among individuals within sibships. Under the conditions and within the statistical power of the study there was no relationship between fitness-related quantitative trait variation and that seen at presumed-neutral microsatellite loci in these outbred populations.
\end{abstract}

Keywords: anuran amphibians, fitness, heterozygosity, mean $d^{2}$, microsatellites.

\section{Introduction}

The relationship between biological fitness and genetic diversity at neutral loci has a long history of investigation (e.g. Mitton \& Grant, 1984; Ledig, 1986). Underpinning such work is the concept that heterozygosity is positively related to fitness. Under one hypothesis, high levels of heterozygosity across an arbitrarily chosen set of neutral loci are presumed to represent genome-wide heterogeneity, and thus overdominance at loci directly involved in fitness traits. Alternatively, low levels of heterozygosity may simply reflect the increased fixation of deleterious alleles at specific, fitness-related loci by drift or inbreeding. Most tests of these hypotheses have measured variation at allozyme loci and, although many positive correlations of heterozygosity with fitness attributes have been reported in a wide range of organisms (e.g. Britten, 1996), there is concern that negative results may be under-recorded. Certainly no consensus has emerged about the relationship, if any, between generalized heterozygosity and biological fitness (David, 1998).

Most recently, the development of new genetic markers such as microsatellites has renewed interest in this subject for at least two reasons. First, they tend

*Correspondence. E-mail: t.j.c.beebee $@$ sussex.ac.uk to be more polymorphic than allozymes and by resolving greater amounts of variation should provide a more powerful and sensitive test of generalized heterozygosity (Sunnucks, 2000). Secondly, by virtue of their mutation mechanism, microsatellite alleles differ in size in a manner that can be related to their history. Microsatellites mutate primarily (though not exclusively) by stepwise changes in the number of repeat units, and this process is biased towards increasing allele size (Schlotterer, 2000). The larger the difference in allele sizes, the longer the inferred time since coalescence. A new measure reflecting these differences, mean $d^{2}$, has been developed and applied to microsatellite data as a further test of relative outbreeding (Coulson et al., 1998). Thus, whereas heterozygosity primarily measures the consequences of recent breeding patterns, mean $d^{2}$ is related to more distant events in population lineages. Despite these developments, however, there have as yet been very few reports of studies relating microsatellite diversity to fitness attributes.

Amphibians are particularly useful organisms for fitness studies because larval growth and developmental rates, timing of and size at metamorphosis are all well authenticated fitness attributes (Wilbur \& Collins, 1973; Wilbur, 1980). For most species, especially those breeding in temporary ponds, rapid larval growth and development are essential for survival. Previous studies 
with amphibians using allozymes have yielded conflicting results, some showing diversity-fitness correlations (e.g. Hitchings \& Beebee, 1998) and others not (e.g. Wright \& Guttman, 1995). We have shown previously that mean heterozygosity across eight microsatellite loci in natterjack toads (Bufo calamita) correlated strongly $(r>0.9)$ with larval growth rate when interpopulation comparisons were made (Rowe et al., 1999). However, that investigation was concerned with populations that differed widely in size, degree of isolation and diversity at microsatellite loci. The present study attempted to test the hypothesis that a relationship between fitness attributes and microsatellite diversity also exists within relatively large, outbred anuran populations open to immigration from neighbouring sites. To this end one population of each of two species, B. calamita and the common frog Rana temporaria, was investigated.

\section{Methods}

\section{Study populations and sampling methods}

In spring 1999 small sections of five spawn strings from $B$. calamita and of five spawn clumps from $R$. temporaria, each section containing 50-100 fertile eggs, were obtained in the field and returned immediately to the laboratory. Bufo calamita was sampled on the Ainsdale sand dunes in Merseyside, UK. This site maintains a population of several thousand adults and is subject to immigration from other large populations immediately to the north and south (Rowe et al., 2000). All the spawn strings used came from different ponds to minimize the likelihood of obtaining half sibship samples. Although this is one of the most polymorphic B. calamita sites in the UK with respect to microsatellite diversity (Rowe et al., 1998), the levels of variation as analysed subsequently were insufficient to demonstrate unique parentage unequivocally in all cases. Females of both species under study produce only one spawn string or clump (Beebee \& Griffiths, 2000), so all certainly had unique mothers, and on the basis of the microsatellite analysis at least three of the $B$. calamita spawn strings (and very probably all of them) also had unique fathers. Rana temporaria was sampled at a park pond in Brighton, UK. This pond is used by several tens of adults and is open to immigration from animals using a large number of neighbouring ponds. On the basis of allozyme analysis it was known to be one of the most polymorphic frog populations in the area (Hitchings \& Beebee, 1997). In this case, subsequent microsatellite analysis confirmed that all five samples had unique mothers and fathers, and thus that there were no half sibships.

\section{Experimental design and rearing of larvae}

The experimental plan was to raise larvae individually under controlled conditions that generated two distinctive stress levels (high and low food supply). The extent of stress could not be anticipated in advance with certainty, but because there is some evidence that heterosis is maximized under stress (Wright \& Guttman, 1995) it was important to ensure that appropriate experimental conditions were provided. For both species, each section of spawn was allowed to hatch in separate containers. Single larvae immediately after hatch (developmental stage 22 for $B$. calamita, stage 23 for R. temporaria: Gosner, 1960) were transferred to plastic beakers containing either $1 \mathrm{~L}$ ( $R$. temporaria) or $0.5 \mathrm{~L}$ (B. calamita) of dechlorinated tapwater and maintained thereafter in a constant temperature room at $20^{\circ} \mathrm{C}$ with a $12: 12 \mathrm{~h}$ dark/light cycle. B. calamita was put into a smaller volume because this species has small larvae that prefer shallower water than $R$. temporaria (Beebee \& Griffiths, 2000). Under 'high food' regimes, each larva was provided with approximately $70 \mathrm{mg}$ powdered rabbit food per week for the first four weeks of development and $100 \mathrm{mg}$ per week thereafter. Under 'low food' regimes each larva of $R$. temporaria received just $1.5 \mathrm{mg}$ in the first week, $5 \mathrm{mg}$ in the second week, $15 \mathrm{mg}$ in each of weeks three and four and then $70 \mathrm{mg}$ per week thereafter. The low food regime for B. calamita differed somewhat. As with $R$. temporaria, $1.5 \mathrm{mg}$ was given in the first week but $5 \mathrm{mg}$ was given in weeks two and three, and $15 \mathrm{mg}$ per week thereafter. These lower rations took account of the fact that $B$. calamita larvae are substantially smaller than those of $R$. temporaria, and even at these low levels some food was often left uneaten at the end of each week. High food conditions were those which, on the basis of previous experience, were likely to support growth rates comparable with those seen in natural ponds. Water was changed in each container every week. For each sibship of each species, 12 larvae were reared under 'high food' and 12 under 'low food' regimes, giving a total of 120 larvae per species. Beakers with larvae from the different sibships were arranged randomly on laboratory shelves and maintained in the same positions for the duration of the experiment. Because growth and development under low food conditions was extremely slow for B. calamita, only animals from the high food trials were used for genetic analysis. The low food treatment was strictly limiting of growth but was used to ascertain whether variances of growth, development or metamorphosis timing responded differently to increased stress and thus to indicate which was under strongest selection pressure. The expectation was that traits under the strongest selection would maintain the lowest variance (Maynard Smith, 
1989). At approximately 7-day intervals, with occasional omissions, every larva was gently removed from the water, transferred to a small weighing boat, water removed with a fine-tipped plastic pasteur pipette and larval wet mass measured to the nearest $0.1 \mathrm{mg}$ on a laboratory balance. The Gosner (1960) developmental stage was noted and the animal returned to its beaker, normally all within 1 minute. A series of preliminary tests demonstrated that this weighing procedure was accurate and reproducible. Thus, weighing the same animal up to five times yielded consistent mass estimates within a range of $2.8-5.8 \%$ of the overall mean. The experiment was continued through to metamorphic climax (Gosner stage 46, full tail resorption) for both species. All individuals from the high food regimes were killed and preserved in ethanol at the end of the experiment, or earlier if they died during development, for subsequent genetic analysis. Taken together the experimental design was intended to allow comparisons to be made at three levels, notably across all individuals, among sibships, and within sibships.

\section{Microsatellite analyses}

DNA was extracted using a Chelex-based protocol (Rowe et al., 1998) and used in polymerase chain reaction (PCR) amplifications with $\alpha^{33} \mathrm{P}$-dATP (direct incorporation) and primers for microsatellite loci previously characterized in these species, as described elsewhere (Rowe et al., 1997; Rowe \& Beebee, 2001). Eight polymorphic loci were available for $B$. calamita, five of which were polymorphic at Ainsdale (Rowe et al., 1998) and seven polymorphic loci free of null allele effects, as well as one bi-allelic marker, were available for $R$. temporaria at the Sussex site (Rowe \& Beebee, 2001). PCR products were analysed by electrophoresis through $6 \%$ polyacrylamide gels followed by autoradiography and scoring of alleles against an M13 DNA size marker (Rowe et al., 1997). Genotype data were complete, and all loci were scored successfully for all individuals.

\section{Statistical methods}

Data analysis, after transformation where necessary to normalize residuals, was carried out using the STATISTIX program (Analytical Software, Tallahassee, FL). Survival of larvae to metamorphosis was given a binary score $(0$ or 1$)$ and investigated using a simple logistic regression model testing the full range of potentially independent morphological and genetic variables. Pearson correlations and one-way analysis of variance (ANOVAs) were employed with Bonferroni corrections for multiple tests where appropriate. Power analysis was carried out as described by Cohen (1977). Heterozygos- ity for each individual was calculated as the mean across all loci. Mean $d^{2}$, outbreeding $d^{2}$ and scaled $d^{2}$ were all calculated for each individual as described by Coulson et al. (1999). Briefly, mean $d^{2}$ is the difference in numbers of dinucleotide repeats per microsatellite locus averaged across all scored loci (with homozygotes scoring 0); outbreeding $d^{2}$ is calculated in the same way but excluding homozygous loci in each individual; and scaled $d^{2}$ is the average $d^{2}$ at each locus scaled by the variance at that locus. Outbreeding $d^{2}$ is most likely to be relevant where there is significant population substructuring, for instance (as was the case in our study) when populations are not completely isolated from one another. Scaling of $d^{2}$ reflects an attempt to remove any effects of different mutation rates between loci by making the statistic linearly proportional to coalescence time. The bi-allelic locus in R. temporaria was omitted from mean $d^{2}$ calculations but included in those for heterozygosity. In $B$. calamita all the genetic estimators were normally distributed, while in $R$. temporaria this was true only of heterozygosity. All three $d^{2}$ measures in this species were successfully normalized before analysis by $\log _{10}$ transformations.

\section{Results}

\section{Growth and development of larvae}

Patterns of larval growth and development for both species, under conditions of high and low food supply, are shown in Fig. 1. In all cases mass increased approximately linearly through much of the development period but declined as expected after the onset of metamorphic climax (Gosner stage 42, emergence of forelimbs). This rate of mass loss was not consistently arrested at the end of metamorphosis (stage 46) and was so severe that no attempts were made to quantify metamorph size. Differences between individuals measured at different times on the same day would have rendered comparisons meaningless. Growth and development rates were estimated for each experiment over periods of approximate linearity (details given in legend to Table 1), truncated in some cases by increasing mortality rates.

Rana temporaria responded to low food regimes by a reduction in both growth and development, with the former generally more severely affected than the latter (Table 1). The time taken to metamorphosis was approximately doubled under low relative to high food conditions. By contrast, under low food conditions B. calamita neither grew nor developed beyond Gosner stages 25-26 (pre hindlimb bud emergence). These larvae experienced zero survival to metamorphosis, dying off progressively through the experiment. Larvae 

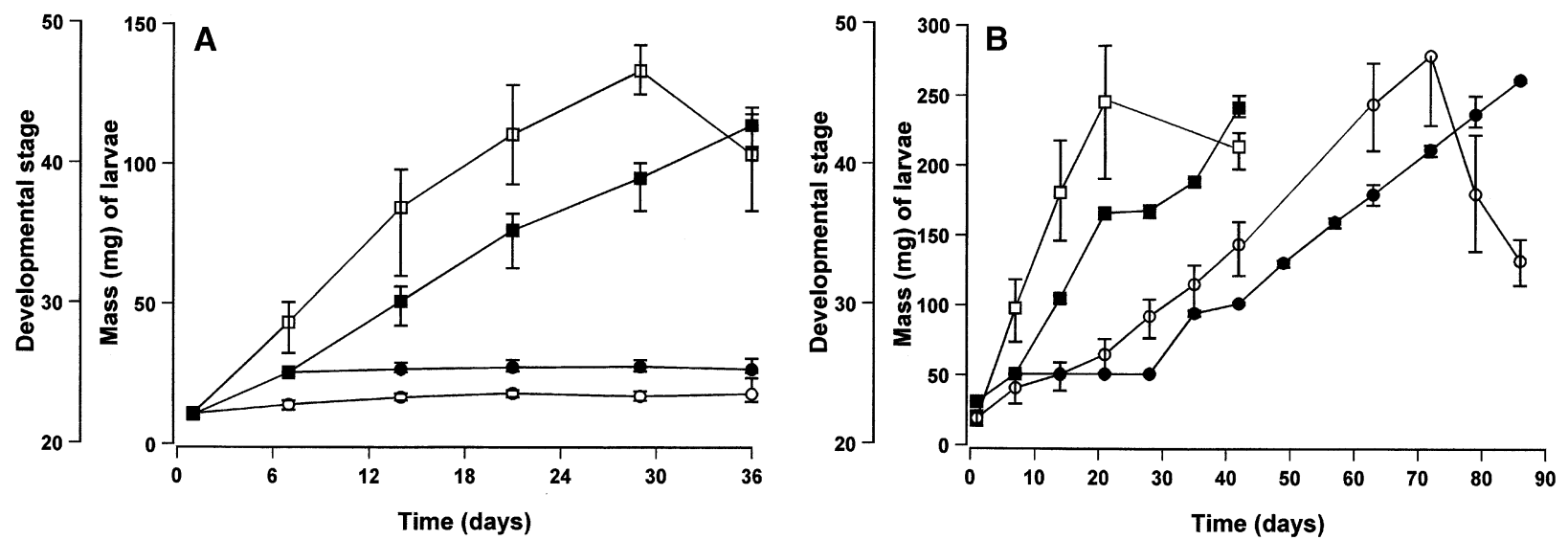

Fig. 1 Growth and development of anuran larvae. (A) B. calamita; (B) R. temporaria. Solid symbols: developmental rates; open symbols: larval masses. Square symbols: high food treatments; circular symbols: low food treatments. Data are averages of the five sibship means and error bars show ranges of these averages.

Table 1 Summary growth and survival statistics. Data are for total numbers of individuals across all sibships. Numbers in parentheses are SE expressed as percentages of means. Growth and development rates were estimated across the following times: B. calamita high food: days 1-21; R. temporaria high food: days 1-21 (growth), 7-21 (development); R. temporaria low food: days 21-42 (growth), 28-72 (development)

\begin{tabular}{|c|c|c|c|c|c|}
\hline Species & $\begin{array}{l}\text { Food } \\
\text { regime }\end{array}$ & $\begin{array}{l}\text { Mean growth } \\
\text { rate in } \mathrm{mg} / \text { day }\end{array}$ & $\begin{array}{l}\text { Mean } \\
\text { development } \\
\text { rate in units/day }\end{array}$ & $\begin{array}{l}\text { Survival } \\
\text { to metamor- } \\
\text { phosis }(\%)\end{array}$ & $\begin{array}{l}\text { Mean time to } \\
\text { metamorphosis } \\
\text { in days }\end{array}$ \\
\hline \multirow[t]{2}{*}{ B. calamita } & High & $4.70(25.6)$ & $0.65(20.1)$ & 88.3 & $34.8(9.4)$ \\
\hline & Low & $0.32(49.3)$ & - & 0 & - \\
\hline \multirow[t]{2}{*}{ R. temporaria } & High & $10.76(18.8)$ & $0.82(4.9)$ & 75.0 & 39.5 (5.4) \\
\hline & Low & $3.74(31.8)$ & 0.35 (8.6) & 61.7 & 76.5 (5.6) \\
\hline
\end{tabular}

in all other treatments experienced much higher survival rates than normally occur in wild populations, but survival was always less than $100 \%$ even under the high food regimes. Although generally high survival rendered this parameter relatively uninformative as a fitness measure, in logistic regression analyses all three of the species $\times$ treatments with $>0 \%$ survival (i.e. excluding B. calamita at low food, Table 1) best fitted a simple model in which survival was significantly correlated with development rate. No other independent variables, either alone or in combination, and including the genetic ones (see below), improved on this model. Thus, for $B$. calamita at high food, regression of survival against development rate yielded $P=0.006$ with $94.7 \%$ correct classification. The corresponding results for $R$. temporaria at high food gave $P=0.0319,74.6 \%$ correctly classified, and $R$. temporaria at low food gave $P=0.0048$ with $78.2 \%$ correct classification.

In the three experiments where there was survival to metamorphosis (i.e. excepting $B$. calamita with low food), growth and development rates correlated strongly with each other and inversely with time to metamorphosis. However, in all these experiments development rates correlated more strongly (by factors of 1.4-5.8) than growth rates with the time to onset of metamorphosis. These development rate $\times$ metamorphosis time correlations ranged between -0.39 ( $R$. temporar$i a \times$ high food) to -0.72 ( $R$. temporaria $\times$ low food) with an average of -0.58 . Growth rate $\times$ metamorphosis time correlations ranged between -0.12 and -0.45 , with an average of -0.27 . Variance, expressed using standard deviation as a percentage of the mean, was lower for metamorphosis time and development rate than for growth rate in $R$. temporaria. For $B$. calamita at high food all variances were relatively high and those of development rate and growth rate were similar. Low food increased the variances of fitness attributes in both species, with a tendency to affect growth and developmental rates more than the timing of metamorphosis in R. temporaria. 


\section{Variations in growth patterns and genetic diversity}

Both species of anurans exhibited some sibship-related features of growth and development. Likely maternal effects were tested for by examining possible correlations between growth or development rates and the starting sizes (masses) of newly hatched (Gosner stage 22 or 23) larvae. These correlations were measured separately under low and high food conditions, and across all individuals, as well as across sibship means. In none of these tests (a total of 20 correlations) was there anything approaching a significant relationship, even without Bonferroni corrections.

Growth characteristics and genetic measures of the five $B$. calamita sibships at high food levels are summarized in Table 2. There were no significant differences between sibships in average time to metamorphosis (ANOVA $F=2.51$, d.f. $=4, P=0.0543$ ), but there were differences in growth rate $(F=3.19$, d.f. $=4$, $P=0.0204)$ and especially in development rate $(F=5.35$, d.f. $=4, P=0.0011)$. At the two extremes, mean growth and development rates of sibship 3 larvae were $16 \%$ and $7 \%$ higher, respectively, than the overall averages and they metamorphosed just over 2 days earlier than the overall mean. By contrast, larvae in sibship 5 grew and developed on average $18 \%$ and $20 \%$ slower, respectively, than the overall mean and metamorphosed nearly two days later than average. They also experienced atypically low overall survival. Sibship 3 larvae (the fastest) therefore grew and developed some $35-40 \%$ faster than those in sibship 5 (the slowest).

Because under high food regimes the survival of both B. calamita and R. temporaria was $>0$ but $<100 \%$, and mean differences in fitness parameters were apparent between sibships, demonstrating that substantial variation occurred at this stress level, genetic measurements were taken of animals reared under these conditions rather than the low food ones. For B. calamita there was, in any case, no choice because there was no progressive development under the more stressful low food regime.
Bufo calamita exhibited sibship differences in the various genetic parameters. There were, however, fairly strong correlations between some of these measures when estimated across all individuals so they cannot be considered as fully independent. Thus, mean heterozygosity correlated with mean $d^{2}(r=0.79)$ and with scaled $d^{2}(r=0.59)$; mean $d^{2}$ also correlated with mean outbreeding $d^{2}(r=0.77)$. Broadly similar correlations were apparent when sibship means (as in Table 2) were examined. Sibships varied in mean heterozygosity (ANOva $F=4.84$, d.f. $=4, P=0.0022)$, mean $d^{2}(F=4.70$, d.f. $=4, P=0.0024)$ and mean outbreeding $d^{2}(F=$ 4.60, d.f. $=4, P=0.003)$ but not in mean scaled $d^{2}$ $(F=0.41$, d.f. $=4, P=0.8026)$. Although sibship 3 with the highest growth and development rates also had the highest mean heterozygosity and highest mean $d^{2}$, there were no significant correlations between any of the fitness and genetic measures either across all individuals, across sibships, or across individuals within sibships. It was notable, for example, that the slowest growing sibship (5) had the highest mean outbreeding $d^{2}$ estimate. Correlations were made across all individuals as well as between sibship means, for which statistical power (with $n=5$ ) was relatively low. Although individuals within sibships were equally inbred, they differed substantially in individual mean heterozygosity and in individual mean $d^{2}$ estimates. For these comparisons (with $n=60$ for each species, $\alpha=0.05$ and a one-tailed test) the probabilty of detecting a 'moderate' correlation of $r \geq 0.3$ (Cohen, 1977) was 0.76 . By contrast, correlations of $>0.75$ between sibship data would be necessary for detection with a probability of $>0.5$.

Growth characteristics and genetic measures of the five $R$. temporaria sibships at high food levels are summarized in Table 3 . As with B. calamita there were no significant differences between sibships in mean time to metamorphosis (ANOVA $F=1.41$, d.f. $=4, P=0.2491$ ) but there were differences in growth rate $(F=9.35$, d.f. $=4, P<0.0001)$ and development rate $(F=6.72$, d.f. $=4, P=0.0002$ ). Larvae of sibship 4 grew and developed on average about $16 \%$ and $3.5 \%$, respectively, faster than the overall mean rates. At the other

Table 2 Growth and genetic characteristics of B. calamita sibships. Data are means for each sibship under high food rearing conditions. Units are as described in Table 1 and Methods

\begin{tabular}{lccccccccc}
\hline Sibship & $\begin{array}{c}\text { Start } \\
\text { mass (mg) }\end{array}$ & $\begin{array}{c}\text { Growth } \\
\text { rate }\end{array}$ & $\begin{array}{c}\text { Development } \\
\text { rate }\end{array}$ & $\begin{array}{c}\text { Survival to } \\
\text { metamorphosis (\%) }\end{array}$ & $\begin{array}{c}\text { Time to } \\
\text { metamorphosis }\end{array}$ & $H_{\mathrm{o}}$ & Mean $d^{2}$ & $\begin{array}{c}\text { Mean } d^{2} \\
\text { (out) }\end{array}$ & $\begin{array}{c}\text { Mean } d^{2} \\
\text { (scaled) }\end{array}$ \\
\hline 1 & 12.0 & 4.89 & 0.70 & 91.7 & 34.6 & 0.42 & 5.76 & 12.96 & 0.13 \\
2 & 8.9 & 4.49 & 0.67 & 91.7 & 36.1 & 0.45 & 8.55 & 19.54 & 0.19 \\
3 & 11.7 & 5.48 & 0.71 & 91.7 & 32.7 & 0.73 & 14.02 & 17.40 & 0.17 \\
4 & 11.0 & 4.84 & 0.68 & 91.7 & 34.4 & 0.45 & 5.93 & 12.20 & 0.17 \\
5 & 10.8 & 3.88 & 0.52 & 75.0 & 36.6 & 0.48 & 13.15 & 25.47 & 0.17 \\
\hline
\end{tabular}


Table 3 Growth and genetic characteristics of $R$. temporaria sibships. Data are means for each sibship under high food rearing conditions. Units are as described in Table 1 and Methods

\begin{tabular}{lccccccccc}
\hline Sibship & $\begin{array}{c}\text { Start } \\
\text { mass (mg) }\end{array}$ & $\begin{array}{c}\text { Growth } \\
\text { rate }\end{array}$ & $\begin{array}{c}\text { Development } \\
\text { rate }\end{array}$ & $\begin{array}{c}\text { Survival to } \\
\text { metamorphosis (\%) }\end{array}$ & $\begin{array}{c}\text { Time to } \\
\text { metamorphosis }\end{array}$ & $H_{\mathrm{o}}$ & Mean $d^{2}$ & $\begin{array}{c}\text { Mean } d^{2} \\
\text { (out) }\end{array}$ & $\begin{array}{c}\text { Mean } d^{2} \\
\text { (scaled) }\end{array}$ \\
\hline 1 & 13.8 & 8.56 & 0.78 & 66.7 & 38.9 & 0.52 & 38.98 & 63.21 & 0.010 \\
2 & 24.42 & 10.75 & 0.82 & 83.3 & 40.4 & 0.58 & 62.42 & 91.16 & 0.067 \\
3 & 14.03 & 11.44 & 0.84 & 66.7 & 39.2 & 0.50 & 33.65 & 73.08 & 0.010 \\
4 & 22.32 & 12.49 & 0.85 & 75.0 & 38.5 & 0.53 & 81.37 & 134.03 & 0.063 \\
5 & 19.92 & 10.72 & 0.82 & 83.3 & 40.2 & 0.65 & 26.51 & 36.1 & 0.062 \\
\hline
\end{tabular}

extreme, sibship 1 larvae grew and developed some $21 \%$ and $5 \%$, respectively, slower than the overall mean rates. Sibship 4 larvae thus grew about $45 \%$ faster than those of sibship 1, and developed about $9 \%$ faster.

Again, the few correlations between the various genetic parameters tended to be different from those found in B. calamita. Thus, across all individuals in $R$. temporaria heterozygosity correlated with scaled $d^{2}$ $(r=0.51)$, while mean $d^{2}$ correlated with outbreeding $d^{2}$ $(r=0.93)$. Across sibship means there were no strong correlations between heterozygosity and the other genetic parameters, but all three types of $d^{2}$ were intercorrelated with $r$-values $>0.65$. There were no significant differences between sibships in mean heterozygosity $(F=2.23$, d.f. $=4, P=0.0798)$ but there were differences in mean $d^{2}(F=4.04$, d.f. $=4, P=0.0064)$, outbreeding $d^{2} \quad(F=3.43, \quad$ d.f. $=4, \quad P=0.0147)$ and scaled $d^{2}$ $(F=15.13$, d.f. $=3, P<0.0001)$. As with $B$. calamita, however, there were no strong or significant correlations between any of the fitness and genetic measures, irrespective of whether comparisons were made across all individuals (with statistical power as described above for $B$. calamita), across the sibship means or across individuals within sibships.

\section{Discussion}

Growth and development measurements of larvae of both anurans reared under controlled conditions supported the hypothesis that development rate and timing of metamorphosis are strongly selected quantitative traits. The tighter association of development rather than growth rate with metamorphosis timing is in accord with observations by Smith-Gill \& Berven (1979) on North American anurans. Timing of metamorphosis, in particular, showed relatively little intraspecific variance even under conditions of strict food limitation in the two species that survived under this regime. Although $R$. temporaria and B. calamita may in general be under different selection pressures on account of their differential susceptibilities to predation (Werner, 1986), there will clearly be an optimal metamorphosis time for any particular species and this was reflected in the laboratory results. Also apparent under the controlled laboratory conditions were significant differences between individuals and between sibships of the two species in both growth and development rates. The latter, on account of its association with metamorphosis time, was of particular interest as a fitness trait. There is no doubt that these parameters are of critical importance in wild populations and in B. calamita, for example, larval growth rate and survival to metamorphosis are strongly correlated in natural ponds (Bardsley \& Beebee, 1998). Even under laboratory conditions, where survival was artificially high in the absence of competition or predation, there was evidence of such a linkage in B. calamita and R. temporaria.

There were also substantial differences between individuals and between sibships of both these species in the various measurements of genetic diversity at microsatellite loci. However, no significant correlations were found between any of the genetic parameters and any of the fitness measures in either species. It is difficult to predict the likely effect size and, thus, the suitability of the present experimental design with respect to statistical power, but it is extremely likely that effects comparable with those seen between fitness and microsatellite heterozygosity would have been detected among populations of B. calamita reared under comparable laboratory conditions $(r=0.919$; Rowe et al., 1999). Previous studies across a wide range of taxa have often found much smaller effects (typically with $r=0.1-0.2$; David, 1998), but these investigations mostly used allozymes that have much low levels of detectable heterozygosity than microsatellites. This lower level of variation may compromise estimates of correlation strength because many polymorphisms remain unseen. Furthermore, many of the earlier studies reporting low correlations were carried out in the field under conditions in which environmental heterogeneity and stochastic effects would very likely have generated substantial background noise, above which genetic effects on fitness can be difficult to resolve. There has been no previous 
work, as far as we know, comparing mean $d^{2}$ and fitness in amphibian populations, but mammalian studies have found strong correlations in some situations both for harbour seals and red deer (Coltman et al., 1998; Coulson et al., 1998, 1999).

There could be several reasons for finding no association between quantitative traits relevant to fitness and genetic measures based on neutral loci within outbred amphibian populations as studied here. Apart from a weak effect not detectable with the statistical power available herein, the most obvious is the possibility that selection acts primarily at loci influencing growth and survival in a manner unrelated to genome-wide patterns of diversity. On the other hand, the microsatellite measurements may have been inappropriate or inadequate as indicators of genomic diversity. The $d^{2}$ statistic is, for example, presumably affected by recombination rates that will tend to homogenize intergenomic differences over time. Relatively small numbers of loci, albeit all that were available, were used and raising statistical power by using more might reveal weak correlations not apparent in the present study. There is also the question of whether alternative fitness attributes, such as embryonic development (pre Gosner stage 22) or postmetamorphic growth may have shown associations with the genetic markers. For the species studied herein, however, the value of larval growth and development rates as primary fitness indicators is very clear (e.g. Bardsley $\&$ Beebee, 1998). It seems certain that any relationship between microsatellite polymorphism and fitness within these outbred anuran populations must, at best, be much weaker than that seen among $B$. calamita populations.

The question arises as to why this difference exists. Interpopulation correlations between fitness and microsatellite heterozygosity previously demonstrated in B. calamita (Rowe et al., 1999) were strong. Alleles were not evenly distributed across populations and in the smallest ones polymorphic loci tended to have skewed allele frequency distributions often with one very common allele and one or two rare ones. In this situation low heterozygosity was apparent but nevertheless the loci were not out of Hardy-Weinberg equilibrium. It may well be that rapid population declines generating bottleneck effects were primarily responsible for the interpopulation differences observed in B. calamita and that under more normal circumstances (i.e. stable populations experiencing migration from neighbours) there are no heterosis effects reflected in neutral loci. Clearly, other species will need to be studied before acceptable generalizations can be made, but it is important to report lacks of association and thus avoid possible bias in future literature surveys.
Despite nearly a century of study, the genetic basis of heterosis has not been resolved unequivocally although some recent reports have indicated that epistasis may be more important than simple dominance or overdominance (McGoldrick \& Hedgecock, 1997; Yu et al., 1997). As pointed out by McGoldrick \& Hedgecock, judicious use of well-characterized microsatellites may help to distinguish between loci under selection and those linked to selected loci, and this may turn out to be their most valuable contribution in future studies of heterosis.

\section{Acknowledgements}

We thank the Leverhulme Trust for financial support and English Nature for access to B. calamita samples at Ainsdale.

\section{References}

BARDSLEY, L. AND BEEBEE, T. J. C. 1998. Interspecific competition between Bufo larvae under conditions of community transition. Ecology, 79, 1751-1760.

BeEbeE, T. J. C. AND GRIfFITHS, R. A. 2000. Amphibians and Reptiles. Harper Collins, London.

BRITTEN, H. B. 1996. Meta-analyses of the association between multilocus heterozygosity and fitness. Evolution, 50, 2158-2164.

COHEN, J. 1977. Statistical Power Analysis for the Behavioural Sciences. Academic Press, New York.

COlTMAN, D. W., BOWEN, w. D. AND WRIGHT, J. M. 1998. Birth weight and neonatal survival of harbour seal pups are positively correlated with genetic variation measured by microsatellites. Proc. R. Soc. B, 265, 803-809.

COUlson, T., Albon, S., SlAte, J. AND PEMBerton, J. 1999. Microsatellite loci reveal sex-dependent responses to inbreeding and outbreeding in red deer calves. Evolution, 53. 1951-1960.

COUlSON, T. N., PEMBERTON, J. M., ALbON, S. D., BEAUMONT, M., MARSHALL, T. C., SLATE, J. ET AL. 1998. Microsatellites reveal heterosis in red deer. Proc. R. Soc. B, 265, 489-495.

DAVID, P. 1998. Heterozygosity-fitness correlations: new perspectives on old problems. Heredity, 80, 531-537.

GOSNER, K. L. 1960. A simplified table for staging anuran embryos and larvae with notes on identification. Herpetologica, 16, 183-190.

HITCHINGS, S.P. AND BEEBEE, T. J.C. 1997. Genetic substructuring as a result of barriers to gene flow in urban common frog (Rana temporaria) populations: implications for biodiversity conservation. Heredity, 79, 117-127.

HITCHINGS, S. P. AND BEEBEE, T. J. C. 1998. Loss of genetic diversity and fitness in common toad (Bufo bufo) populations isolated by inimical habitat. J. Evol. Biol., 11, 269-283.

LEDIG, F. T. 1986. Heterozygosity, heterosis and fitness in outbreeding plants. In: Soulé, M. E. (ed.) Conservation Biology (the Science of Scarcity and Diversity), pp. 77-104. Sinauer, New York. 
MAYNARD SMITH, J. 1989. Evolutionary Genetics. Oxford University Press, Oxford.

McGOLDRICK, D. J. AND HEDGECOCK, D. 1997. Fixation, segregation and linkage of allozyme loci in inbred families of the Pacific oyster Crassostrea gigas (Thunberg): implications for the causes of inbreeding depression. Genetics, 146, 321-334.

MitTon, J. B. AND GRANT, M. C. 1984. Associations among protein heterozygosity, growth rate and developmental homeostasis. Ann. Rev. Ecol. Syst., 15, 479-499.

ROWE, G. AND BEEBEE, T. J. C. 2001. Polymerase chain reaction primers for microsatellite loci in the common frog Rana temporaria. Mol. Ecol. Notes, 1, 6-7.

ROWE, G., BEEBEE, T. J. C. AND BURKE, T. 1997. PCR primers for polymorphic microsatellite loci in the anuran amphibian Bufo calamita. Mol. Ecol., 6, 401-402.

ROWE, G., BEEBEE, T. J. C. AND BURKe, T. 1998. Phylogeography of the natterjack toad Bufo calamita in Britain: genetic differentiation of native and translocated populations. Mol. Ecol., 7, 751-760.

ROWE, G., BEEBEE, T. J. C. AND BURKE, T. 1999. Microsatellite heterozygosity, fitness and demography in natterjack toads, Bufo calamita. Anim. Conserv., 2, 85-92.
ROWE, G., BEEBEE, T. J. C. AND BURKe, T. 2000. A microsatellite analysis of natterjack toad (Bufo calamita) metapopulations. Oikos, 88, 641-651.

SCHLOTTERER, C. 2000. Evolutionary dynamics of microsatellite DNA. Chromosoma, 109, 365-371.

SMITH-GILl, S. J. AND BERVEN, K. A. 1979. Predicting amphibian metamorphosis Amer. Nat., 113, 563-585.

SUNNUCKS, P. 2000. Efficient genetic markers for population biology. Trends Ecol. Evol., 15, 199-203.

WERNER, E. E. 1986. Amphibian metamorphosis: growth rate, predation risk, and the optimal size at transformation. Amer. Nat., 128, 319-341.

wilbur, H. M. 1980. Complex life cycles. Ann. Rev. Ecol. Syst., 11, 67-93.

WILbUR, H. M. AND COLLINS, J. P. 1973. Ecological aspects of amphibian metamorphosis. Science, 182. 1305-1314.

WRIGHT, M. F. AND GUTTMAN, S. I. 1995. Lack of an association between heterozygosity and growth rate in the wood frog, Rana sylvatica. Can. J. Zool., 73, 569-575.

YU, S. B., LI, J. X., XU, C. G., TAN, Y. F., GAO, Y. J., LI, X. H. ET $A L$. 1997. Importance of epistasis as the genetic basis of heterosis in an elite rice hybrid. Proc. Natl. Acad. Sci. U.S.A., 94, 9226-9231. 